\title{
Patient-Specific Model-Based Investigation of Speech Intelligibility and Movement during Deep Brain Stimulation
}

\author{
Mattias Åström ${ }^{a}$ Elina Tripolitic Marwan I. Hariz ${ }^{\text {b, c }}$ Ludvic U. Zrinzo ${ }^{c}$ \\ Irene Martinez-Torres ${ }^{c}$ Patricia Limousin ${ }^{c}$ Karin Wårdella \\ a Department of Biomedical Engineering, Linköping University, Linköping, and ${ }^{\mathrm{b}}$ Department of Neurosurgery, \\ University Hospital, Umeå, Sweden; ' Institute of Neurology, University College, London, UK
}

\section{Key Words}

Deep brain stimulation - Dysarthria $\cdot$ Speech intelligibility

Parkinson's disease $\cdot$ Electric field $\cdot$ Fasciculus

cerebellothalamicus

\begin{abstract}
Background/Aims: Deep brain stimulation (DBS) is widely used to treat motor symptoms in patients with advanced Parkinson's disease. The aim of this study was to investigate the anatomical aspects of the electric field in relation to effects on speech and movement during DBS in the subthalamic nucleus. Methods: Patient-specific finite element models of DBS were developed for simulation of the electric field in 10 patients. In each patient, speech intelligibility and movement were assessed during 2 electrical settings, i.e. $4 \mathrm{~V}$ (high) and $2 \mathrm{~V}$ (low). The electric field was simulated for each electrical setting. Results: Movement was improved in all patients for both high and low electrical settings. In general, high-amplitude stimulation was more consistent in improving the motor scores than low-amplitude stimulation. In 6 cases, speech intelligibility was impaired during high-amplitude electrical settings. Stimulation of part of the fasciculus cerebellothalamicus from electrodes positioned medial and/or posterior to the center of the subthalamic nucleus
\end{abstract}

was recognized as a possible cause of the stimulation-induced dysarthria. Conclusion: Special attention to stimulation-induced speech impairments should be taken in cases when active electrodes are positioned medial and/or posterior to the center of the subthalamic nucleus.

Copyright $\odot 2010$ S. Karger AG, Basel

\section{Introduction}

Deep brain stimulation (DBS) of the subthalamic nucleus (STN) is widely used to treat motor symptoms in patients with advanced Parkinson's disease (PD) [1-3]. As many as $60-80 \%$ of the PD patients develop hypokinetic speech disorders associated with the disease $[4,5]$. Common speech manifestations are monotony of pitch and loudness, a harsh and breathy voice with a variable rate and decreased articulation [6,7]. A combination of these symptoms may, in the late stage of the disease, produce nonintelligible speech. By tradition, these features of hy-

Conflict of Interest: Marwan Hariz and Ludvic Zrinzo occasionally received travel expenses from Medtronic to lecture at meetings.

\section{KARGER}

Fax +41613061234

E-Mail karger@karger.ch

www.karger.com
() 2010 S. Karger AG, Basel

$1011-6125 / 10 / 0884-0224 \$ 26.00 / 0$

Accessible online at:

www.karger.com/sfn
Mattias Åström, MSc

Department of Biomedical Engineering

Linköping University

SE-58185 Linköping (Sweden)

Tel. +46736290978, E-Mail matas@imt.liu.se 
pokinetic dysarthria have been linked to the motor symptoms rigidity and akinesia $[8,9]$. However, several studies have shown that clinically effective stimulation of the STN, with a significant improvement of the motor symptoms, may have an independent influence on speech. Along with substantially improved motor symptoms, some patients may obtain negative stimulation-induced effects on speech during STN DBS [10-16]. At other times, there may be no effects at all $[17,18]$, or sometimes positive effects on speech during clinically effective STN stimulation [19-22]. This may suggest that limb and speech motor systems are different in their organization and control [17]. However, few studies have been performed specifically assessing speech during STN stimulation.

Recently, the acute effects of bilateral STN DBS on speech intelligibility and movement in 14 patients were studied by Tripoliti et al. [23]. In that study, it was hypothesized that current spread into the pallidofugal fibers [ansa lenticularis (al) and fasciculus lenticularis (fl)] and the fasciculus cerebellothalamicus (fct) could be responsible for the stimulation-induced speech deficits. In the present study, a subgroup of $10 \mathrm{PD}$ patients from the study of Tripoliti et al. was further studied in order to investigate the electric field generated by DBS in relation to the anatomy. A recently developed method for setting up patient-specific, finite element computer models of DBS [24] was used to create models of each patient and to simulate and visualize the electric field during various electrical settings. The overall aim of this study was to relate the anatomical aspect of the simulated electric field to acute effects on speech intelligibility and movement.

\section{Method}

\section{Patient Selection}

Ten English-speaking patients with advanced PD (2 women) with a mean age of 59 years (SD 7) at the time of surgery were included in the study. The patients had received bilateral DBS in the STN (Model 3389 DBS ${ }^{\mathrm{TM}}$ Lead and Kinetra ${ }^{\circledR}$ neurostimulation system, Medtronic, Inc. USA) and were enrolled in this study based on their stimulation-induced effects on speech intelligibility. The patients fell into three groups: group A (patients 1 and 2) included patients with substantially impaired speech intelligibility during 4-volt amplitude settings compared to off stimulation; group B (patients 3-6) included patients with slightly impaired speech intelligibility during 4-volt amplitude settings compared to off stimulation, and group C (patients 7-10) included patients whose speech intelligibility was not impaired during 4-volt amplitude settings. In these particular patients, the stimulation-induced impairment of speech intelligibility was considered sub- stantial when the reduction was $30-53 \%$, slight when the reduction was $7-10 \%$ and not impaired when the reduction was $\leq 1 \%$. The local ethics committee at the National Hospital for Neurology and Neurosurgery, London, UK, approved the study (REC No. 05/Q0512/108) and the patients gave their informed consent.

\section{Stereotactic Imaging}

All patients had undergone surgery based on stereotactic $\mathrm{T}_{2^{-}}$ weighted magnetic resonance images (MRI) with sequences enabling visualization of the STN [25]. The anatomical location of the electrodes was confirmed on immediate postoperative stereotactic MRI with the Leksell frame still attached to the head. The electrode contacts located closest to the center of the STN were used as active electrode contacts for chronic stimulation. In order to identify the contacts closest to the center of the STN the postoperative stereotactic fast spin-echo $T_{2}$-weighted MRI, where artifacts produced by the electrodes are visible, were studied using the FrameLink Planning Station ${ }^{\mathrm{TM}}$ (Medtronic, Minneapolis, Minn., USA). Both the pre- and postoperative MRI were acquired on a 1.5-tesla scanner (GE Signa; General Electric Medical Systems, Wisc., USA) with a voxel volume of $0.98 \times$ $0.98 \times 2.0 \mathrm{~mm}^{3}$ without slice separation. The images were later interpolated by the PACS to a voxel volume of $0.49 \times 0.49 \times 2.0$ $\mathrm{mm}^{3}$.

Assessments of Speech Intelligibility and Movement

Assessments of speech intelligibility and movement were performed by Tripoliti et al. [23] at least 6 months after STN DBS surgery. Anti-parkinsonian medications were withdrawn the night before the day of investigation. During the assessments, both the investigator and the patients were blinded to the electrical DBS settings. Speech intelligibility and movement were evaluated during monopolar stimulation with an electric potential of 0,2 , and $4 \mathrm{~V}$ (off, low- and high-amplitude stimulation, respectively), while the pulse width and frequency remained unchanged at $60 \mu \mathrm{s}$ and $130 \mathrm{~Hz}$. Subsequent to every change of amplitude, the patients rested for $15 \mathrm{~min}$ before the next evaluation.

The evaluation of speech consisted of the following: sustained vowel phonation 'ah' for 3 repetitions (the patient is asked to say 'ah' for as long as possible); assessment of intelligibility for the dysarthric speech [26], and a 60-second monologue about a subject of the patient's choice. Speech intelligibility was scored as the percentage of words that were correctly transcribed by a native English speaker blinded to the stimulation conditions. Movement was evaluated using the motor part of the Unified Parkinson's Disease Rating Scale (UPDRS III). A more detailed description of the assessment protocols has been presented by Tripoliti et al. [23].

\section{Patient-Specific Models}

Three-dimensional patient-specific finite element computer models of bilateral DBS in the STN were set up for each of the 10 patients. Preoperative $\mathrm{T}_{2}$-weighted stereotactic MRI was used to create tissue models of each brain and postoperative stereotactic MRI was used to position the DBS electrodes at their true positions in the brain models. Each of the preoperative MRI voxels was classified into material groups, such as gray matter, white matter and cerebrospinal fluid. The classified MRI voxels were allotted isotropic electrical conductivity properties at a frequency of $130 \mathrm{~Hz}$ from Andreuccetti's online database [27] where the 


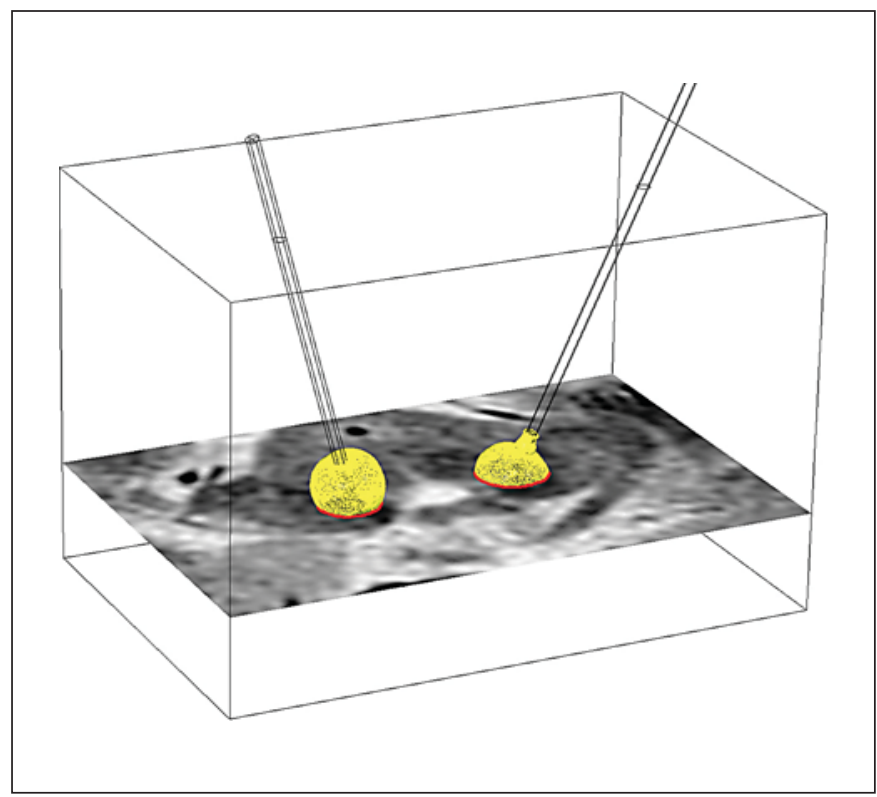

Fig. 1. Patient-specific simulation of DBS in the STN. The electric field was visualized with isolevels at $0.2 \mathrm{~V} / \mathrm{mm}$. The isolevels were traced onto axial and coronal images. In this figure, the trace is colored in red which indicates substantially decreased speech intelligibility.

electrical conductivity of cerebrospinal fluid was set to $2 \mathrm{~S} / \mathrm{m}$, gray matter to $0.09 \mathrm{~S} / \mathrm{m}$, white matter to $0.06 \mathrm{~S} / \mathrm{m}$ and blood to $0.7 \mathrm{~S} / \mathrm{m}$. A random neuronal orientation was assumed, thus isotropic electrical conductivity values were used. Particular MRI voxels may contain more than one tissue, giving rise to partial volume effects. Therefore, a linear step function was used to allot approximated electrical physical properties to the voxels containing a mixture of different tissues. Two DBS electrodes with a radius of $0.635 \mathrm{~mm}$ and contact lengths of $1.5 \mathrm{~mm}$ separated by $0.5 \mathrm{~mm}$ (Model 3389 $\mathrm{DBS}^{\mathrm{TM}}$ Lead, Medtronic, Inc. USA) were modeled and positioned in each brain model. Further detailed description of the method for creating patient-specific models and simulations of DBS can be found in Åström et al. [28].

\section{Patient-Specific Simulations}

Electric field simulations were performed for all patients with 2- and 4-volt electric potential settings which were used during the assessments. Before implementing the settings into the model, the electric potential settings were normalized from 4 to $3.5 \mathrm{~V}$, and from 2 to $1.7 \mathrm{~V}$ according to the voltage threshold correction factors for the Medtronic Kinetra neurostimulation system (Medtronic, Inc. USA) [29]. The distribution of the electric potential in the vicinity of the electrodes was calculated using the equation for steady currents [30]. The model was solved on a 64-bit Linux computer $(3.6 \mathrm{GHz}$ Intel Xeon processor, 16 GB RAM) for approximately 2,500,000 number of degrees of freedom using Comsol Multiphysics 3.3 (Comsol Multiphysics $A B$, Sweden).

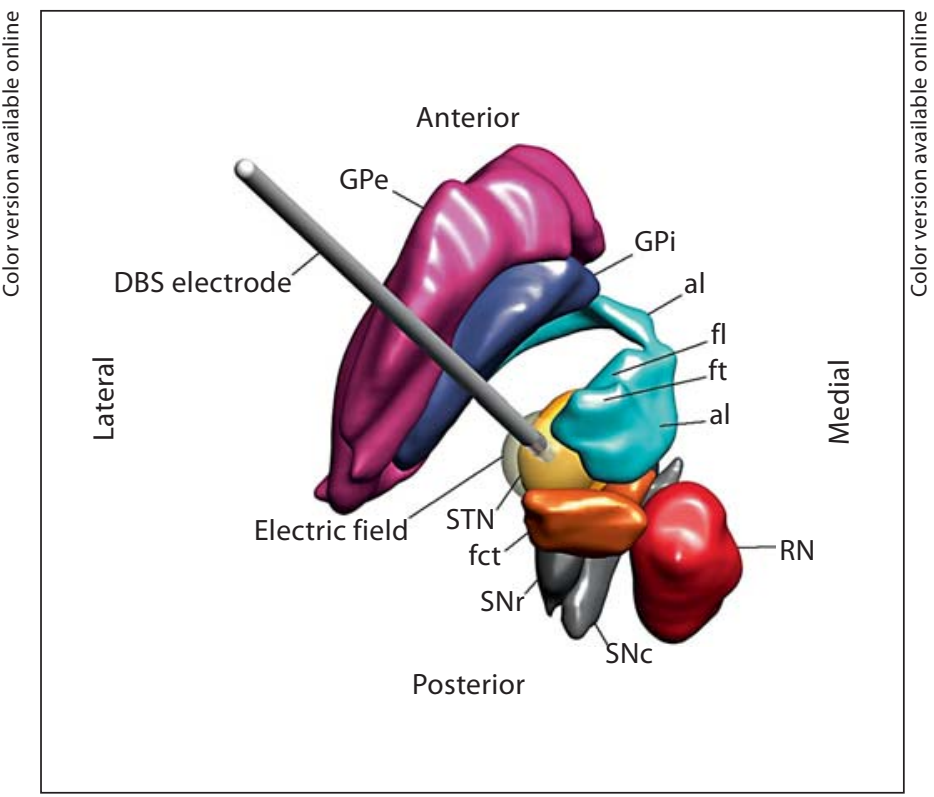

Fig. 2. Superior view of a three-dimensional atlas model. The three-dimensional atlas model included the STN, red nucleus $(\mathrm{RN}), \mathrm{fct}, \mathrm{al}, \mathrm{fl}, \mathrm{ft}$, substantia nigra pars reticulata ( $\mathrm{SNr}$ ), substantia nigra pars compacta ( $\mathrm{SNc}$ ), internal segment of the globus pallidus (GPi) and external segment of the globus pallidus (GPe), together with an animated DBS electrode placed in the posterodorsal area of the STN. An electric field was animated with a transparent isolevel in white color.

\section{Visualization}

The electric field was visualized in three dimensions with isolevels at $0.2 \mathrm{~V} / \mathrm{mm}$ together with the anatomy on two-dimensional color-coded axial and coronal slices. The contours of the electric field isolevels were traced onto the axial and coronal slices where they were color-coded according to the assessment scores on speech intelligibility. Red color indicated substantially impaired speech intelligibility (30-53\% impairment), orange color indicated slightly impaired speech intelligibility (7-10\% impairment), and white color indicated no reduction of speech intelligibility ( $\leq 1 \%$ impairment) (fig. 1$)$. In cases with improved speech intelligibility by $10-40 \%$, the electric field isolevel trace was colored green. Surrounding structures of the STN, for example the pallidofugal fibers and fct, were identified and traced onto the model images with the help of atlases presented in Gallay et al. [31] and Morel [32].

\section{Atlas Model}

In order to improve the understanding of the anatomical relation between the STN and its surrounding structures, a threedimensional atlas model of the STN, red nucleus, fct, al, fl, fasciculus thalamicus (ft), substantia nigra pars reticulata, substantia nigra pars compacta, globus pallidus interna and globus pallidus externa was created in Matlab 7.0 (The MathWorks, USA). The anatomical model was based on axial images from a 
Table 1. Speech intelligibility and UPDRS III scores during $2 \mathrm{~V}$, $4 \mathrm{~V}$, and off stimulation

\begin{tabular}{|c|c|c|c|c|c|c|c|}
\hline \multirow{2}{*}{$\begin{array}{l}\text { Patient } \\
\text { No. }\end{array}$} & \multirow{2}{*}{ Group } & \multicolumn{3}{|c|}{ Speech intelligibility, \% } & \multicolumn{3}{|c|}{ UPDRS III score } \\
\hline & & $2 \mathrm{~V}$ & $4 \mathrm{~V}$ & off & $2 \mathrm{~V}$ & $4 \mathrm{~V}$ & off \\
\hline 1 & A & 45 & 7 & 60 & 52 & 28 & 71 \\
\hline 2 & $\mathrm{~A}$ & 84 & 55 & 85 & 19 & 21 & 41 \\
\hline 3 & $\mathrm{~B}$ & 70 & 20 & 30 & 33 & 33 & 62 \\
\hline 4 & B & 65 & 50 & 60 & 34 & 26 & 48 \\
\hline 5 & B & 63 & 61 & 70 & 29 & 31 & 50 \\
\hline 6 & B & 68 & 55 & 62 & 52 & 32 & 45 \\
\hline 7 & $\mathrm{C}$ & 74 & 75 & 76 & 47 & 14 & 51 \\
\hline 8 & $\mathrm{C}$ & 77 & 83 & 75 & 42 & 24 & 57 \\
\hline 9 & $\mathrm{C}$ & 68 & 55 & 53 & 21 & 29 & 42 \\
\hline 10 & $\mathrm{C}$ & 55 & 50 & 45 & 56 & 25 & 64 \\
\hline
\end{tabular}

Speech intelligibility was measured as the percentage of intelligible words by a native English-speaking listener.

stereotactic atlas of the human thalamus and basal ganglia by Morel [32]. The atlas model also included a modeled DBS electrode positioned in the posterodorsal part of the STN with an animated electric field at contact 2 .

\section{Results}

Patient-specific simulations of the electric field were visualized with isolevels at $0.2 \mathrm{~V} / \mathrm{mm}$ and traced onto axial and coronal images. The traced isolevels were colorcoded according to the assessment scores on speech intelligibility. Anatomical structures in the surrounding of the electrodes were marked onto the axial and coronal images. In addition, a three-dimensional anatomical atlas model of the STN and adjacent structures and fiber paths was created and visualized for improved anatomical information during the interpretation of the simulations (fig. 2).

\section{Speech Intelligibility}

The patients in group A (patients 1 and 2) suffered from substantial stimulation-induced impairment of speech intelligibility during high-amplitude stimulation (i.e. $4 \mathrm{~V}$ ) (table 1). These 2 patients had at least 1 active electrode contact positioned in the posterior part of the STN. Apart from the STN, the simulated electric field isolevel also covered a major part of the fct during highamplitude stimulation (fig. 3). Patient 1 suffered from stimulation-induced impairment of speech intelligibility
Table 2. The position of the left (L) and right (R) active electrode contacts were described in relation to the center of the STN

\begin{tabular}{|c|c|c|c|c|c|}
\hline \multirow[t]{2}{*}{$\begin{array}{l}\text { Patient } \\
\text { No. }\end{array}$} & \multirow[t]{2}{*}{ Electrode contact position } & \multicolumn{4}{|c|}{$\begin{array}{l}\text { Electric field isolevel } \\
\text { covered }\end{array}$} \\
\hline & & fct & al & $\mathrm{fl}$ & $\mathrm{ft}$ \\
\hline \multirow[t]{2}{*}{1} & dorsal, posterior & $\mathrm{C}$ & $\mathrm{N}$ & $\mathrm{C}$ & $\mathrm{C}$ \\
\hline & dorsal & $\mathrm{N}$ & $\mathrm{S}$ & $\mathrm{C}$ & $\mathrm{C}$ \\
\hline \multirow[t]{2}{*}{2} & center & $S$ & $\mathrm{~N}$ & $\mathrm{C}$ & $\mathrm{N}$ \\
\hline & posterior & $\mathrm{C}$ & $\mathrm{N}$ & $\mathrm{C}$ & $\mathrm{N}$ \\
\hline \multirow[t]{2}{*}{3} & ventral, medial & $\mathrm{C}$ & $\mathrm{N}$ & $\mathrm{C}$ & $\mathrm{C}$ \\
\hline & ventral, medial, posterior & $\mathrm{C}$ & $\mathrm{N}$ & $\mathrm{C}$ & $\mathrm{C}$ \\
\hline \multirow[t]{2}{*}{4} & medial & $\mathrm{N}$ & $\mathrm{N}$ & $\mathrm{C}$ & $\mathrm{C}$ \\
\hline & ventral, medial, posterior & $\mathrm{C}$ & $\mathrm{N}$ & $\mathrm{C}$ & $\mathrm{S}$ \\
\hline \multirow[t]{2}{*}{5} & medial & $\mathrm{S}$ & $\mathrm{N}$ & $\mathrm{C}$ & $\mathrm{C}$ \\
\hline & medial & S & $\mathrm{S}$ & $\mathrm{C}$ & $\mathrm{C}$ \\
\hline \multirow[t]{2}{*}{6} & ventral & S & $\mathrm{N}$ & $\mathrm{S}$ & $\mathrm{N}$ \\
\hline & posterior & $\mathrm{S}$ & $\mathrm{N}$ & $S$ & $\mathrm{~N}$ \\
\hline \multirow[t]{2}{*}{7} & dorsal & $\mathrm{N}$ & $\mathrm{N}$ & $\mathrm{C}$ & $\mathrm{C}$ \\
\hline & dorsal & $\mathrm{N}$ & $\mathrm{N}$ & $\mathrm{C}$ & $\mathrm{C}$ \\
\hline \multirow[t]{2}{*}{8} & dorsal & $\mathrm{N}$ & $\mathrm{C}$ & $\mathrm{C}$ & $\mathrm{C}$ \\
\hline & dorsal & $\mathrm{N}$ & $\mathrm{C}$ & $\mathrm{C}$ & $\mathrm{C}$ \\
\hline \multirow{2}{*}{$\begin{array}{l}\mathrm{L} \\
\mathrm{R}\end{array}$} & dorsal, medial & $\mathrm{N}$ & S & $\mathrm{C}$ & $\mathrm{C}$ \\
\hline & dorsal, medial & $\mathrm{N}$ & $\mathrm{C}$ & $\mathrm{C}$ & $\mathrm{C}$ \\
\hline \multirow[t]{2}{*}{10} & ventral, medial & $S$ & $\mathrm{~N}$ & $\mathrm{C}$ & $\mathrm{S}$ \\
\hline & dorsal, anterior & $\mathrm{N}$ & $\mathrm{N}$ & $\mathrm{C}$ & $\mathrm{C}$ \\
\hline
\end{tabular}

The spatial distribution of the electric field isolevels during high-amplitude stimulation $(4 \mathrm{~V})$ was described in relation to $\mathrm{fct}$, al, $\mathrm{fl}$, and ft. $\mathrm{N}=$ Did not cover the structure; $\mathrm{S}=$ slightly covered the structure; $\mathrm{C}=$ considerably covered the structure.

also during low-amplitude stimulation (i.e. $2 \mathrm{~V}$ ). The electric field isolevel in relation to fct, al, $\mathrm{fl}$, and $\mathrm{ft}$ is presented in table 2.

The speech intelligibility in group B (patients 3-6) was noticeably impaired during high-amplitude settings, although to a lesser degree than for the patients in group $\mathrm{A}$ (table 1). The patients of group B had at least 1 electrode contact positioned in the posterior and/or medial part of the STN. In patients 3, 4 and 6, at least 1 of the active contacts was also positioned ventral to the center of the STN. At least 1 of the electric field isolevels covered part of the fct during high-amplitude stimulation (fig. 4). In patient 5 , speech intelligibility was also reduced during low-amplitude stimulation. The electric field isolevel in relation to $\mathrm{fct}, \mathrm{al}, \mathrm{fl}$, and $\mathrm{ft}$ is presented in table 2 .

The patients in group C (patients 7-10) did not suffer from stimulation-induced speech impairments during high- or low-amplitude stimulation (table 1). Patients 7-9 

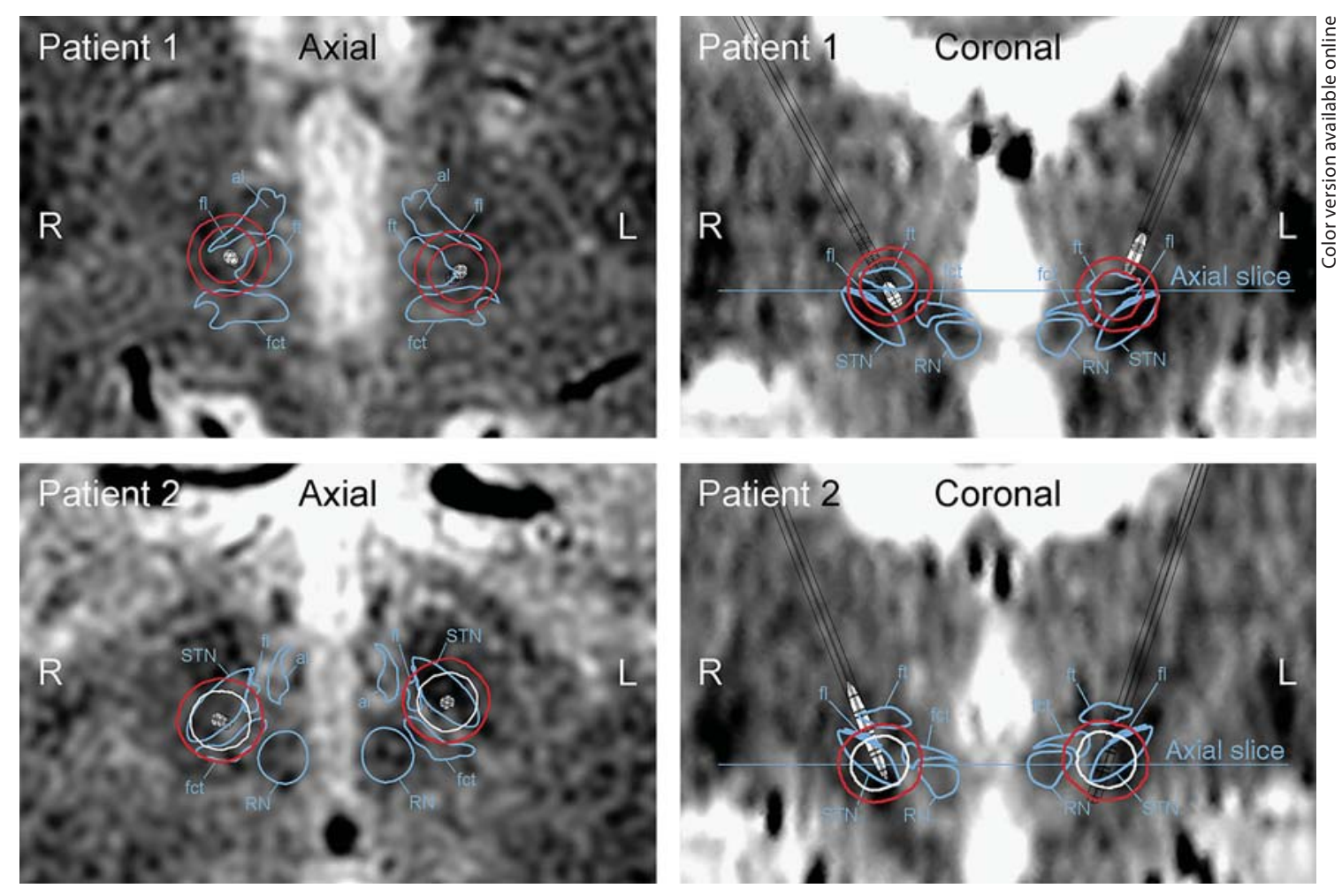

Fig. 3. Axial and coronal images of group A (patients 1 and 2). These patients suffered from substantial stimulation-induced impairment of speech intelligibility during high-amplitude stimulation (i.e. $4 \mathrm{~V}$ ). These patients had at least 1 of the active electrode contacts located in the posterior part of the STN. The boundaries of the red nucleus (RN), the STN, and the fct are marked in the axial and coronal images when present. The contours of the electric field isolevels are traced and color-coded where red indicates substantially decreased speech intelligibility and white indicates no effect on speech intelligibility.

had electrode contacts positioned in the dorsal part of the STN area, while the left electrode contact in patient 10 was located more ventrally. This electrode was pulled up approximately $2.5 \mathrm{~mm} 1$ week after the postoperative images were acquired. Although this was compensated for in the model, the position of this electrode is indecisive. The distribution of the electric field isolevels during highamplitude stimulation did not cover part of the fct in patients 7-9, and slightly covered part of the fct in patient 10 (fig. 5). The electric field isolevel in relation to fct, al, $\mathrm{fl}$, and $\mathrm{ft}$ is presented in table 2 .

\section{Movement}

Movement as scored by the UPDRS III was improved in all patients to various degrees during both low- and high-amplitude settings compared to off stimulation (table 1). Patients 2, 3, and 5, had similar motor scores during both low- and high-amplitude stimulation, while patients 1, 6, 7 and 10 showed large differences in the UP-
DRS III between low- and high-amplitude stimulation (fig. 3-5). The electric field isolevel in relation to fct, al, fl, and $\mathrm{ft}$ is presented in table 2 .

\section{Discussion}

In this study, the anatomical aspects of the electric field generated by DBS was studied to improve the understanding of its acute effects on speech intelligibility and movement. The simulations show that speech intelligibility was impaired only when the $0.2 \mathrm{~V} / \mathrm{mm}$ electric field isolevel covered part of the fct. Accordingly, when the electric field isolevel covered a major part of the pallidofugal fibers without covering the fct, speech was not impaired. Movement was improved by DBS for a wide range of electrode contact locations and electrical settings within the STN area. High-amplitude stimulation was more consistent in improving the motor scores than 

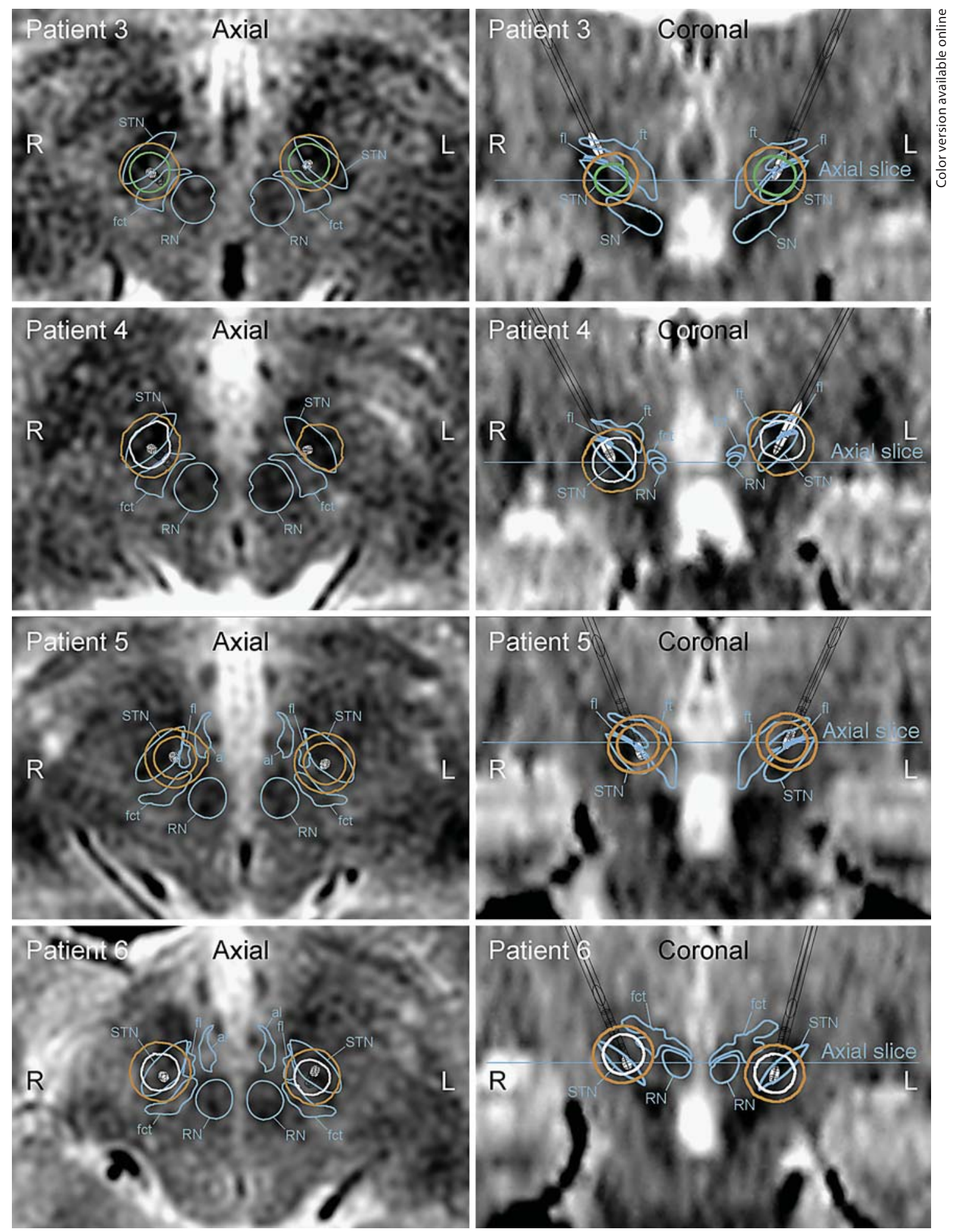

Fig. 4. Axial and coronal images of group B (patients 3-6) whose speech was impaired during high-amplitude settings. In these patients, the $0.2 \mathrm{~V} / \mathrm{mm}$ electric field isolevel covered part of the fct during high-amplitude stimulation. The boundaries of the red nucleus (RN), STN, and fct are marked in the axial and coronal images when present. The contours of the electric field isolevels are traced and color-coded where orange indicates impaired speech intelligibility, green substantially improved speech intelligibility, and white no effect on speech intelligibility. 

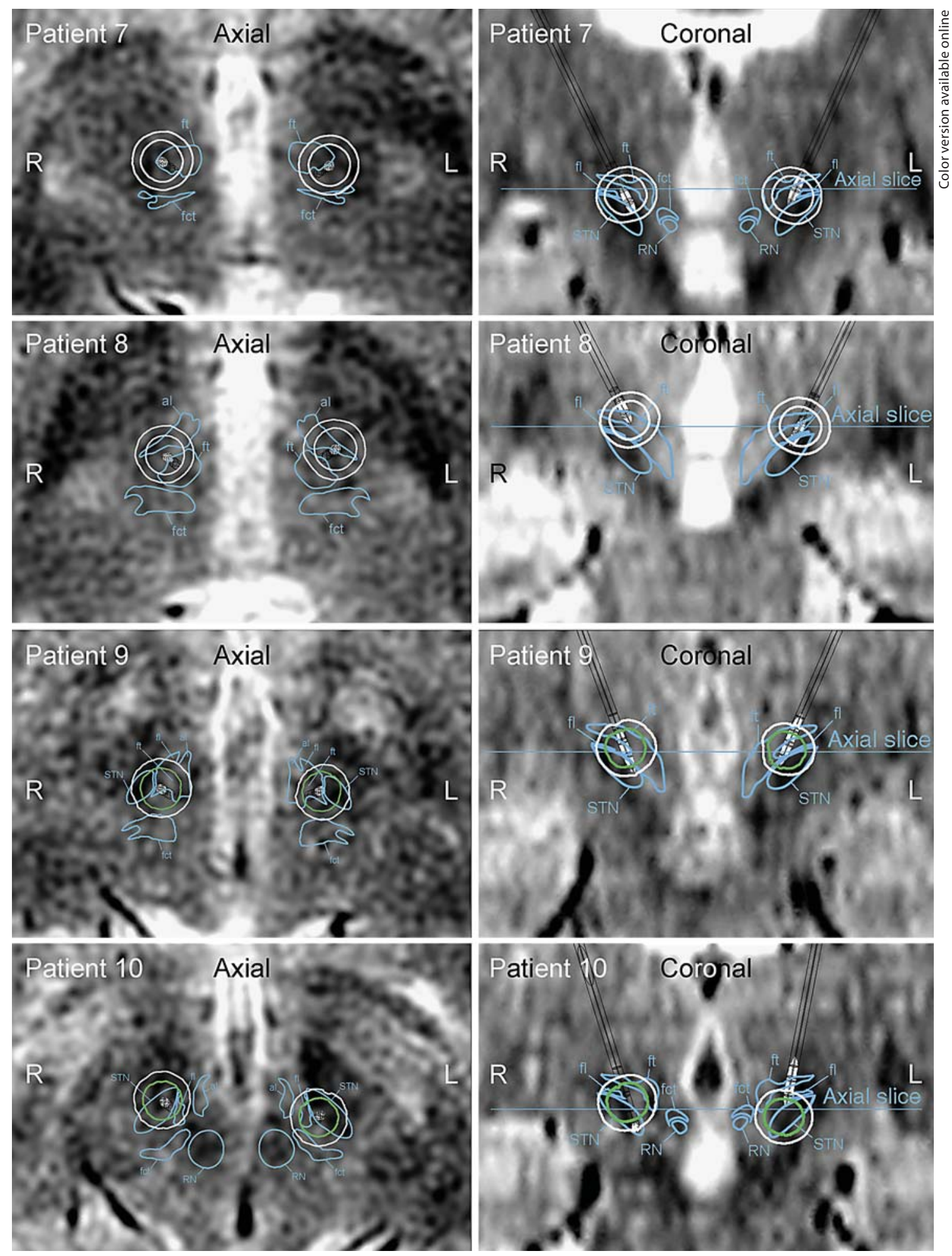

Fig. 5. Axial and coronal images of group C (patients 7-10) who did not suffer from stimulation-induced speech impairments during high- or low-amplitude stimulation. The distribution of the electric field isolevels did not cover part of the fct in patients $7-9$, and slightly covered part of the fct in patient 10 . The bound- aries of the red nucleus (RN), STN, and fct are marked in the axial and coronal images when present. The contours of the electric field isolevels are traced and color-coded where white indicates no effect on speech intelligibility and green substantially improved speech intelligibility. 
low-amplitude stimulation. This was also the case in patients whose speech intelligibility was substantially impaired by the stimulation.

Stimulation-induced speech impairments during STN DBS have often been attributed to current diffusion laterally into the motor limb in the internal capsule, the corticobulbar fibers [2, 15, 33-35]. The simulations showed that patients with stimulation-induced speech impairments had electrodes placed medial and/or posterior to the center of the STN. In these patients, the electric field isolevel during high-amplitude stimulation only slightly extended laterally into the corticobulbar fibers. Thus, it is not likely that the speech impairments were attributed to stimulation of corticobulbar fibers. In 2 cases, patients 4 and 6 , the electric field extended further out into the internal capsule. However, during stimulation of the corticobulbar fibers there is usually a change of sustained phonation and other acoustical parameters. These characteristics were not seen in any of the patients in the present study. The speech of groups A and B (patients 1-6) during high-amplitude stimulation could be described as breathy and hypernasal, with intermittently continuous voicing of hyperfunctional quality and reduced lip, tongue and jaw movement, which led to imprecise articulation [36].

In a study by Plaha et al. [37], stimulation-related dysarthria was noticed in patients with active electrode contacts positioned medially to the STN. The authors believed that stimulation of fibers from the fct that control movements of the vocal cords was likely the cause of the dysarthria. In addition, Velasco et al. [38] found that 3 out of 10 patients suffered from stimulation-induced dysarthria from electrodes placed in the prelemniscal radiation which run medially to the STN and contain cerebellar fibers. These results are in agreement with the present findings. In addition, the fct projects to the motor thalamus with primary projections to the ventral intermediate nucleus [31]. Thus, current spread into the fct may constitute a possible cause of the well-known stimulation-induced speech impairments during DBS in the ventral intermediate nucleus of thalamus.

Speech intelligibility was chosen as the main measure since it is a paramount parameter for communication. However, only the acute effects were assessed which is not always equivalent to the long-term effects. In the present study, the electrode contacts located closest to the center of the STN were chosen as active contacts although these contacts were not always selected clinically for providing the most beneficial effects. Assessments during unilateral stimulation of the STN have suggested that the effect on speech intelligibility is hemisphere specific [39-41]. Although highly relevant, unilateral assessments were not performed in this study in order to keep the examination time reasonable. Moreover, the small sample size of the present study accentuates carefulness when interpreting the results. For a more thorough discussion of the speech investigations, the reader is referred to the study by Tripoliti et al. [23].

It is important to recognize that the patient-specific models and electric field simulations presented in this study only provide a rough estimation of the electric field generated by DBS [28]. The models were limited to isotopic tissue properties which may not provide a correct representation of areas with anisotropic white matter tracts. Most importantly, the $0.2 \mathrm{~V} / \mathrm{mm}$ electric field isolevel should be interpreted as a boundary wherein the electric field is $0.2 \mathrm{~V} / \mathrm{mm}$ or larger, and not as the volume of tissue influenced by the stimulation. Various neural components (soma, axons, and dendrites) are affected differently depending on their size and orientation in the electric field and the volume of tissue influenced by DBS is still not known. The $0.2 \mathrm{~V} / \mathrm{mm}$ isolevel was used in this study for visualization of relative changes of the electric field between high- and low-amplitude stimulation. The uncertainty of the volume of influence exists in parallel with the uncertainty of the brain anatomy and physiology on a detailed level. Atlases presented by Gallay et al. [31] and Morel [32] were used to identify and trace the contours of structures and fiber paths in the surroundings of the STN onto the axial and coronal images. However, these traces only provide an approximation of the true locations of these structures and fiber paths due to for example slight misplacement of the atlas, and patients' individual anatomical variability.

Despite its limitations, this study shows that patientspecific computer models and simulations can be used to provide insights regarding the electric field in relation to the clinical response during DBS. The results indicate that movement can be improved by DBS for a wide range of electrode contact locations and electrical settings within the STN area. Stimulation of the fct may be a possible cause of stimulation-induced dysarthria during STN DBS. Special attention to stimulation induced speech impairments should be taken in cases when active electrodes are positioned medial and/or posterior to the center of the STN. 


\section{Acknowledgements}

This work was supported by the Swedish Foundation for Strategic Research (SSF), Swedish Research Council (VR) and Swedish Governmental Agency for Innovation Systems (VINNOVA grant 311-2006-7661). Support was also received by a grant from the Fondo de Inversion Sanitaria (FIS), Instituto de Salud Carlos
III, Spanish Department of Science and Innovation (grant FI08/00108), the Parkinson's Disease Society UK (grant 4070), Parkinson's Appeal, Brain Research Trust, Medtronic and the National Institutes of Health (grant R01-NS40902). The authors would also like to thank Johannes Johansson, at the Department of Biomedical Engineering, Linköping University, for support with the simulations.

\section{References}

$>1$ Limousin P, Krack P, Pollak P, Benazzouz A, Ardouin C, Hoffmann D, Benabid AL: Electrical stimulation of the subthalamic nucleus in advanced Parkinson's disease. N Engl J Med 1998;339:1105-1111.

-2 Krack P, Batir A, Van Blercom N, Chabardes S, Fraix V, Ardouin C, Koudsie A, Limousin PD, Benazzouz A, LeBas JF, Benabid AL, Pollak P: Five-year follow-up of bilateral stimulation of the subthalamic nucleus in advanced Parkinson's disease. N Engl J Med 2003;349:1925-1934.

>3 Moro E, Scerrati M, Romito LM, Roselli R, Tonali P, Albanese A: Chronic subthalamic nucleus stimulation reduces medication requirements in Parkinson's disease. Neurology 1999;53:85-90.

4 Schulz GM, Grant MK: Effects of speech therapy and pharmacologic and surgical treatments on voice and speech in Parkinson's disease: a review of the literature. J Commun Disord 2000;33:59-88.

$\checkmark 5$ Ramig LO, Dromey C: Aerodynamic mechanisms underlying treatment-related changes in vocal intensity in patients with Parkinson disease. J Speech Hear Res 1996;39:798-807.

$\checkmark 6$ Ho AK, Iansek R, Marigliani C, Bradshaw JL, Gates S: Speech impairment in a large sample of patients with Parkinson's disease. Behav Neurol 1998;11:131-137.

7 Logemann JA, Fisher HB, Boshes B, Blonsky ER: Frequency and cooccurrence of vocal tract dysfunctions in the speech of a large sample of Parkinson patients. J Speech Hear Disord 1978;43:47-57.

$\checkmark 8$ Darley FL, Aronson AE, Brown JR: Clusters of deviant speech dimensions in the dysarthrias. J Speech Hear Res 1969;12:462-496.

-9 Darley FL, Aronson AE, Brown JR: Differential diagnostic patterns of dysarthria. J Speech Hear Res 1969;12:246-269.

-10 Rousseaux M, Krystkowiak P, Kozlowski O, Ozsancak C, Blond S, Destee A: Effects of subthalamic nucleus stimulation on parkinsonian dysarthria and speech intelligibility. J Neurol 2004;251:327-334.

-11 Romito LM, Scerrati M, Contarino MF, Iacoangeli M, Bentivoglio AR, Albanese A: Bilateral high frequency subthalamic stimulation in Parkinson's disease: long-term neurological follow-up. J Neurosurg Sci 2003;47: 119-128.
12 Rodriguez-Oroz MC, Obeso JA, Lang AE, Houeto JL, Pollak P, Rehncrona S, Kulisevsky J, Albanese A, Volkmann J, Hariz MI, Quinn NP, Speelman JD, Guridi J, Zamarbide I, Gironell A, Molet J, PascualSedano B, Pidoux B, Bonnet AM, Agid Y, Xie J, Benabid AL, Lozano AM, Saint-Cyr J, Romito L, Contarino MF, Scerrati M, Fraix V, Van Blercom N: Bilateral deep brain stimulation in Parkinson's disease: a multicentre study with 4 years follow-up. Brain 2005;128: 2240-2249.

13 Törnqvist AL, Schalen L, Rehncrona S: Effects of different electrical parameter settings on the intelligibility of speech in patients with Parkinson's disease treated with subthalamic deep brain stimulation. Mov Disord 2005;20:416-423.

14 Guehl D, Cuny E, Benazzouz A, Rougier A, Tison F, Machado S, Grabot D, Gross C, Bioulac B, Burbaud P: Side-effects of subthalamic stimulation in Parkinson's disease: clinical evolution and predictive factors. Eur J Neurol 2006;13:963-971.

15 Klostermann F, Ehlen F, Vesper J, Nubel K, Gross M, Marzinzik F, Curio G, Sappok T: Effects of subthalamic deep brain stimulation on dysarthrophonia in Parkinson's disease. J Neurol Neurosurg Psychiatry 2008; 79:522-529.

-16 Piboolnurak P, Lang AE, Lozano AM, Miyasaki JM, Saint-Cyr JA, Poon YY, Hutchison WD, Dostrovsky JO, Moro E: Levodopa response in long-term bilateral subthalamic stimulation for Parkinson's disease. Mov Disord 2007;22:990-997.

17 Farrell A, Theodoros D, Ward E, Hall B, Silburn P: Effects of neurosurgical management of Parkinson's disease on speech characteristics and oromotor function. J Speech Lang Hear Res 2005;48:5-20.

18 D’Alatri L, Paludetti G, Contarino MF, Galla S, Marchese MR, Bentivoglio AR: Effects of bilateral subthalamic nucleus stimulation and medication on parkinsonian speech impairment. J Voice 2008;22:365-372.

19 Gentil M, Pinto S, Pollak P, Benabid AL: Effect of bilateral stimulation of the subthalamic nucleus on parkinsonian dysarthria. Brain Lang 2003;85:190-196.
20 Pinto S, Gentil M, Fraix V, Benabid AL, Pollak P: Bilateral subthalamic stimulation effects on oral force control in Parkinson's disease. J Neurol 2003;250:179-187.

21 Dromey C, Kumar R, Lang AE, Lozano AM: An investigation of the effects of subthalamic nucleus stimulation on acoustic measures of voice. Mov Disord 2000;15:11321138.

22 Gentil M, Garcia-Ruiz P, Pollak P, Benabid AL: Effect of stimulation of the subthalamic nucleus on oral control of patients with parkinsonism. J Neurol Neurosurg Psychiatry 1999;67:329-333.

23 Tripoliti E, Zrinzo L, Martinez-Torres I, Tisch S, Frost E, Borrell E, Hariz MI, Limousin P: Effects of contact location and voltage amplitude on speech and movement in bilateral subthalamic nucleus deep brain stimulation. Mov Disord 2008;23:2377-2383.

-24 Åstrom M, Zrinzo LU, Tisch S, Tripoliti E, Hariz MI, Wårdell K: Method for patientspecific finite element modeling and simulation of deep brain stimulation. Med Biol Eng Comput 2009;47:21-28.

25 Hariz MI, Krack P, Melvill R, Jorgensen JV, Hamel W, Hirabayashi $H$, Lenders $M$, Wesslen N, Tengvar M, Yousry TA: A quick and universal method for stereotactic visualization of the subthalamic nucleus before and after implantation of deep brain stimulation electrodes. Stereotact Funct Neurosurg 2003;80:96-101.

26 Yorkston KM, Beukelman DR: Communication efficiency of dysarthric speakers as measured by sentence intelligibility and speaking rate. J Speech Hear Disord 1981;46: 296-301.

27 Andreuccetti D, Fossi R, Petrucci C: Dielectric properties of body tissue. Italian National Research Council, Institute for Applied Physics, Florence, Italy. 2005. http://niremf. ifac.cnr.it/tissprop/.

-28 Åström M, Zrinzo LU, Tisch S, Tripoliti E, Hariz MI, Wårdell K: Method for patientspecific finite element modeling and simulation of deep brain stimulation. Med Biol Eng Comput 2009;47:21-28.

$>29$ Butson CR, McIntyre CC: Differences among implanted pulse generator waveforms cause variations in the neural response to deep brain stimulation. Clin Neurophysiol 2007;118:1889-1894. 
30 Cheng DK: Field and Wave Electromagnetics. Reading, Addison-Wesley Publishing Company Inc, 1989.

- 31 Gallay MN, Jeanmonod D, Liu J, Morel A: Human pallidothalamic and cerebellothalamic tracts: anatomical basis for functional stereotactic neurosurgery. Brain Struct Funct 2008;212:443-463.

32 Morel A: Stereotactic Atlas of the Human Thalamus and Basal Ganglia. New York, Informa Healthcare, 2007.

- 33 Krack P, Fraix V, Mendes A, Benabid AL, Pollak P: Postoperative management of subthalamic nucleus stimulation for Parkinson's disease. Mov Disord 2002;17(suppl 3):S188-S197.

- 34 Pinto S, Gentil M, Krack P, Sauleau P, Fraix V, Benabid AL, Pollak P: Changes induced by levodopa and subthalamic nucleus stimulation on parkinsonian speech. Mov Disord 2005;20:1507-1515.
35 Deuschl G, Herzog J, Kleiner-Fisman G, Kubu C, Lozano AM, Lyons KE, RodriguezOroz MC, Tamma F, Troster AI, Vitek JL, Volkmann J, Voon V: Deep brain stimulation: postoperative issues. Mov Disord 2006 21(suppl 14):S219-S237.

36 Tripoliti E, Limousin P, Tisch S, Borrell E, Hariz M: Speech in Parkinson's disease following subthalamic nucleus deep brain stimulation: preliminary results. J Med Speech Lang Pathol 2006;14:309-315.

37 Plaha P, Ben-Shlomo Y, Patel NK, Gill SS: Stimulation of the caudal zona incerta is superior to stimulation of the subthalamic nucleus in improving contralateral parkinsonism. Brain 2006;129:1732-1747.

38 Velasco F, Jimenez F, Perez ML, CarrilloRuiz JD, Velasco AL, Ceballos J, Velasco M: Electrical stimulation of the prelemniscal radiation in the treatment of Parkinson's disease: an old target revised with new techniques. Neurosurgery 2001;49:293-306.
39 Santens P, De Letter M, Van Borsel J, De Reuck J, Caemaert J: Lateralized effects of subthalamic nucleus stimulation on different aspects of speech in Parkinson's disease. Brain Lang 2003;87:253-258.

40 Wang E, Verhagen Metman L, Bakay R, Arzbaecher J, Bernard B: The effect of unilateral electrostimulation of the subthalamic nucleus on respiratory/phonatory subsystems of speech production in Parkinson's disease - A preliminary report. Clin Linguist Phon 2003;17:283-289.

41 Wang EQ, Metman LV, Bakay RA, Arzbaecher J, Bernard B, Corcos DM: Hemisphere-specific effects of subthalamic nucleus deep brain stimulation on speaking rate and articulatory accuracy of syllable repetitions in Parkinson's disease. J Med Speech Lang Pathol 2006;14:323-334. 